\title{
Carbohydrate-induced manipulation of insulin sensitivity independently of intramyocellular lipids
}

\author{
Louise M. Goff ${ }^{1,2}$, Gary S. Frost ${ }^{2}$, Gavin Hamilton ${ }^{1}$, E. Louise Thomas ${ }^{1}$, \\ Waljit S. Dhillo ${ }^{3}$, Anne Dornhorst ${ }^{3}$ and Jimmy D. Bell ${ }^{1}$ \\ ${ }^{1}$ MRC MRI Unit, Clinical Sciences Centre, ${ }^{2}$ Department of Nutrition \& Dietetics, and ${ }^{3}$ Department of Metabolic Medicine, \\ Division of Investigative Science, Hammersmith Hospital, Imperial College School of Medicine, London W12 OHS, UK
}

(Received 6 February 2002 - Revised 9 October 2002 - Accepted 21 October 2002)

\begin{abstract}
Subjects with insulin resistance have been shown to have higher storage levels of intramyocellular lipid (IMCL) than their insulin-sensitive counterparts. It has been proposed that elevated IMCL stores may be the main cause of insulin resistance. The aim of the present study was to ascertain whether there is a causal relationship between IMCL storage and insulin resistance. IMCL storage was assessed using magnetic resonance spectroscopy and insulin sensitivity was assessed by performing an oral glucose tolerance test. A 4-week intervention of reduction of dietary glycaemic index was used to manipulate insulin sensitivity in a cohort of healthy volunteers; the effects of this intervention on IMCL were measured after 4 weeks of intervention. Significant improvements in the insulin sensitivity index occurred following the dietary intervention (baseline 7.8 (SEM 1.11) v. post-intervention 9.7 (SEM 1.11), $P=0.02$ ). However, there were no changes in IMCL storage levels, suggesting that insulin sensitivity can be manipulated independently of IMCL. This suggests that in healthy volunteers, insulin sensitivity is independent of IMCL storage and the high storage levels that have been found in insulin-resistant subjects may occur as a consequence rather than a cause of insulin resistance.
\end{abstract}

Intramyocellular lipids: Insulin resistance: Insulin sensitivity: Magnetic resonance spectroscopy: Glycaemic index: Carbohydrate

Insulin resistance has been shown to be associated with a significantly increased risk of CHD, hypertension and type 2 diabetes (Reaven, 1994). However, the underlying mechanism associated with the development of insulin resistance is not fully understood.

Recent clinical and animal research has shown a significant positive correlation between insulin resistance and levels of intramyocellular lipid (IMCL) (Falholt et al. 1988; Phillips et al. 1996; Pan et al. 1997; Forouhi et al. 1999; Jacob et al. 1999; Krssak et al. 1999). Studies in rodents have also shown that high-fat feeding results in a parallel increase in insulin resistance and IMCL storage (Kraegen et al. 1991; Storlien et al. 1991) In addition, it has been found recently that troglitazone, a member of the thiazolidinedione group of insulin-sensitising drugs, reduces IMCL storage while improving insulin sensitivity in rodents (Sreenan et al. 1999). This, and other published work, has given renewed impetus to the concept that IMCL may be pivotal, through the Randle cycle, in the development of insulin resistance (Randle et al. 1963). However, it remains unclear whether IMCL stores in muscle are a cause or an effect of insulin resistance.

It is estimated that $25 \%$ of the population are insulin resistant (Reaven, 1995) and this incidence is likely to increase with the rise in obesity; this makes effective lifestyle management an important public health issue. Lifestyle factors, such as dietary modification, have been demonstrated to improve insulin sensitivity (Tremblay, 1995; Torjesen et al. 1997; Saris et al. 1998). Evidence supports the role of carbohydrates in influencing insulin sensitivity (Jenkins et al. 1988; Wolever et al. 1992; Daly et al. 1997; Roche, 1999). Frost et al. (1996) found, using the short insulin tolerance test, that in vivo insulin sensitivity improves following a low-glyaemic-index (GI) diet; this has yet to be investigated using the 'gold standard' clamp procedure for assessing insulin sensitivity. In vitro experiments also show that insulin-stimulated glucose uptake by adipocytes improves following a low-GI diet

\footnotetext{
Abbreviations: GI, glycaemic index; iAUC, incremental area under the curve; IMCL, intramyocellular lipid; NEFA, non-esterified fatty acid; OGTT, oral glucose tolerance test.

* Corresponding author: Dr Gary S. Frost, fax +44 208383 3379, email gfrost@ic.ac.uk
} 
(Frost et al. 1996, 1998). In addition, Salmeron et al. $(1997 a, b)$ found that high-GI diets were positively associated with a greater risk of type 2 diabetes than any type of fat intake. However, evidence from large prospective studies is conflicting: Liu et al. (2000) and Frost et al. (1999) found dietary glycaemic load and/or GI to be directly associated with CHD risk whilst van Dam et al. (2000) report no such association. A possible mechanism by which low-GI diets are protective against CHD is that they improve insulin sensitivity by suppressing non-esterified fatty acid (NEFA) release (Wolever et al. 1995; Stears \& Byrne, 2001). This affects the Randle cycle, promoting glucose utilisation and possibly affecting storage of IMCL.

The hypothesis investigated in the present study was that a low-GI dietary manipulation would improve insulin sensitivity through reducing IMCL storage in a group of healthy male subjects.

\section{Subjects and methods}

\section{Study sample}

Twenty-one healthy white European males without a history of diabetes or chronic disease were recruited. The mean age of the subjects was 40.8 (SEM 2.50) years and the mean BMI was 27.2 (SEM 0.99) $\mathrm{kg} / \mathrm{m}^{2}$. Exclusion criteria included diabetes, CHD and any metabolic disorder or drug treatment known to affect carbohydrate or lipid metabolism. Subjects were also excluded if they had dietary restrictions that would prevent them from adhering to the study protocol or if they had contra-indications for a magnetic resonance scan, such as claustrophobia or metal prostheses. All subjects gave informed written consent and the protocol was approved by the Imperial College School of Medicine, Hammersmith Campus Research Ethics Committee (reference 99/5567).

\section{Methods}

The study consisted of a baseline period of $7 \mathrm{~d}$, followed by an intervention period of 3-4 weeks.

\section{Dietary intake}

Prospective food diaries $(7 \mathrm{~d})$ were collected from the subjects. Portion sizes were assessed and validated using a photographic aid (Nelson et al. 1997). Diaries were analysed for macro- and micronutrient composition using the DietPlan $5^{\text {TM }}$ (Forestfield Software Ltd, Horsham, Surrey, UK) computer package. The GI of the subjects' diets were calculated using published tables of GI for individual foods (Foster \& Miller, 1995) and using the formula derived by Wolever \& Jenkins (1986) for calculating the GI of mixed meals. The dietary assessments were validated using the subjects' estimated energy requirement, calculated using the Schofield equation (Schofield et al. 1985) and Department of Health (1991) recommendations for activity requirements. Dietary assessments that varied from the estimated energy requirement by $\pm 2000 \mathrm{~kJ} / \mathrm{d}$ were rejected.

\section{Anthropometry}

Weight $(\mathrm{kg})$, height $(\mathrm{m})$ and BMI $\left(\mathrm{kg} / \mathrm{m}^{2}\right)$ were measured for each subject in the morning period during a visit to the study centre. Body fat $(\%)$ and waist:hip ratio were measured using the InBody 3.0 (Biospace Co., Ltd, Seoul, South Korea) system, which is a multifrequency segmental bioeletrical impedance method (Thomas et al. 2001).

\section{Oral glucose tolerance test}

Postprandial lipid and carbohydrate metabolism were assessed by means of the oral glucose tolerance test (OGTT). Subjects underwent an overnight fast (minimum $10 \mathrm{~h}$ ) and refrained from alcohol ingestion and strenuous exercise in the $24 \mathrm{~h}$ preceding the test. On arrival, each subject had a cannula placed in an ante-cubital fossa vein in the non-dominant arm. At time point 0 , within a 2 min period, subjects consumed a $75 \mathrm{~g}$ oral glucose load (Lucozade; SmithKline Beecham, Welwyn, Herts., UK). Blood $(10 \mathrm{ml})$ was taken into lithium heparin tubes containing aprotinin (4000 kIU; Bayer, Newbury, Berks., $\mathrm{UK})$ at time points $-20,-10,0,30,60,90,120$, $180 \mathrm{~min}$. Flushes of $\mathrm{NaCl}$ solution $(9 \mathrm{~g} / \mathrm{l}, 5 \mathrm{ml})$ were used to keep the cannula patent throughout the test period. The samples were immediately centrifuged for $10 \mathrm{~min}$ at $3000 \mathrm{rpm}$ at $4^{\circ} \mathrm{C}$ and plasma separated and stored in aliquots at $-20^{\circ} \mathrm{C}$.

\section{Fasting biochemistry}

Fasting glucose, cholesterol, cholesterol particles, triacylglycerol, NEFA and insulin concentrations were measured in the samples from the OGTT.

Plasma glucose concentrations were determined using a glucose-oxidase-based autoanalyser (Technicon; Axon Bayer Diagnostic, Newbury, Berks., UK). Insulin concentrations were determined using a radioimmunoassay (Albano et al. 1972). The inter- and intra-assay CV for this assay were $<10 \%$ and the detection limit of the assay was $2 \mathrm{pmol} / \mathrm{l}$ with $95 \%$ CI. To minimise inter-assay variation, all samples were included in one assay and were analysed on the first freeze-thaw. NEFA concentrations were determined at each time point using the Wako NEFA test kit (Wako Chemicals, Alpha Laboratories Ltd, Eastleigh, Hants., UK) that utilises an enzymatic calorimetric method. Fasting and postprandial plasma triacylglyerol concentrations were determined using Boehringer Mannheim test kits (Boehringer Mannheim, Lewes, E. Sussex, UK). Total fasting cholesterol, LDL-cholesterol and HDL-cholesterol concentrations were determined using an Olympus AU 600 analyser and Olympus reagents (Olympus Diagnostic Systems, Southall, London, UK).

The trapezoidal rule was used to calculate the glucose, insulin, NEFA and triacylglycerol integrated area under the curve (iAUC). This method of calculation is derived from the summation of the mean plasma concentration for each time period subtracted from the mean basal value, multiplied by the number of minutes in the time period. The iAUC derived expresses both the duration 
and magnitude of the plasma response, while correcting for baseline values.

An insulin sensitivity index was calculated according to the formula derived by Matsuda \& DeFronzo (1999). This uses the following equation to estimate insulin sensitivity using the OGTT: $10000 \sqrt{ }(($ fasting glucose $\times$ fasting insulin $) \times($ mean glucose $\times$ mean insulin) during OGTT) .

\section{Magnetic resonance spectroscopy}

${ }^{1} \mathrm{H}$-Magnetic resonance spectroscopy was used to assess IMCL storage; in brief (as we have previously published detailed methodology elsewhere: Rico-Sanz et al. 1998; Forouhi et al. 1999), spectra were acquired using a $1.5 \mathrm{~T}$ Marconi Medical Eclipse system (Marconi Medical Systems, Cleveland, OH, USA) from the soleus (predominantly oxidative muscle fibres), tibialis (predominantly glycolytic fibres) and gastrocnemius (mixed fibre type) muscles of the left lower leg. Subjects lay in a supine position with the left leg immobilised in a $300 \mathrm{~mm}$ diameter quadrature birdcage coil. A clamp device was used to immobilise and measure the positioning and orientation of the leg to ensure that the leg was in an identical position for follow-up scans. Transverse $\mathrm{T}_{1}$-weighted magnetic resonance images (repetition time 600 , echo time $16 \mathrm{~ms}$ ) were acquired for placement of the ${ }^{1} \mathrm{H}$-magnetic resonance spectroscopy voxel, with a slice thickness of $5 \mathrm{~mm}$, a $200 \mathrm{~mm}$ field of view and $192 \times 256$ data matrix. Spectra were obtained without water suppression using a standard PRESS sequence with echo time/repetition time = $135 / 1500 \mathrm{~ms}, 8000 \mathrm{~mm}^{3}$ voxel and 256 averages. Spectra were analysed using the MRUI software package (van den Boogaart et al. 1996; Magnetic Resonance User Interface, 2002). Peak areas for each signal were obtained and lipid resonances were quantified with reference to total creatine after correcting for $T_{1}$ and $T_{2}$ (Rico-Sanz et al. 1998). The reproducibility of this technique has previously been calculated by our group; the inter-examination $\mathrm{CV}$ is 13.6 (SEM 3.5) \% (Rico-Sanz et al. 1998).

\section{Dietary intervention}

After the $7 \mathrm{~d}$ baseline period was completed, subjects began the 4-week intervention period of a low-GI diet. The aim of the dietary intervention was to change only the GI of the diet without affecting other macronutrients. Each subject received written and verbal advice on how to achieve a low-GI diet. The information centred on the basic principal that the starchy carbohydrate at each meal time should consist of a low-GI carbohydrate, for example pasta, rice, wholegrain bread, oats, beans or pulses. All of the foods advised for inclusion in the diet were commonly available in supermarkets. Subjects were not given any specific information or advice on portion sizes; they were advised to eat to appetite and to maintain their body weight throughout the study. The subjects were also requested to maintain a constant level of physical activity throughout the study period.

During the first week of the intervention period the subjects completed a $3 \mathrm{~d}$ food diary that was used to assess appropriateness of changes and to give further advice if required. Advice and encouragement was given throughout the intervention period by regular telephone consultations.

During the fourth week of the intervention, each subject revisited the study centre for anthropometric measurements to be repeated and a further OGTT and magnetic resonance scan. A $7 \mathrm{~d}$ food diary was completed at this time to ensure compliance throughout the whole study period and this record was used for overall assessment of the dietary intervention.

\section{Statistical analysis}

Statistical analyses were performed using SPSS Release 9.0 for Windows (SPSS Inc., Chicago, IL, USA).

The results in tabular and graphical form are shown as mean values with their standard errors. Data were tested for normality using the Shapiro-Wilk W test. The paired Student's $t$ test and Pearson's correlation coefficient were used for statistical analysis. Statistical significance was taken as $P<0.05$.

\section{Results}

Eighteen subjects completed the protocol; two subjects were unable to tolerate the cannulation procedure and therefore withdrew from the study and one subject was excluded due to self-prescribing a substantial fatty acid supplement during the manipulation period.

\section{Dietary findings}

The mean duration of intervention was $25 \mathrm{~d}$. The subjects' baseline and post-intervention macronutrient intakes, as assessed through the $7 \mathrm{~d}$ dietary records, are shown in Table 1. All dietary assessments were within $\pm 2000 \mathrm{~kJ}$ of the subjects' estimated energy requirements and therefore believed to be a valid estimation of their dietary intake. The subjects were requested to maintain usual activity levels during the intervention. All subjects reported complying with this request on follow-up. The subjects achieved a significant reduction in the GI of their diets (baseline 80 (SEM 1.9) v. post-intervention 70 (SEM 1.7), $P=0 \cdot 002$ ) without significant changes to other macronutrients in their diets.

\section{Anthropometry}

The subjects' anthropometric characteristics at baseline and post-intervention are shown in Table 2. The subjects' mean BMI $(27.3$ (SEM 1.03$) \mathrm{kg} / \mathrm{m}^{2}$ ) indicates that the group were, on average, overweight but not obese $(\mathrm{BMI}<25, n$ 8; BMI $25-30, n 6$; BMI $>30, n 4)$. After intervention, there were non-significant changes in BMI, $\%$ body fat and waist:hip ratio, although the mean body weight had decreased by $0.6 \mathrm{~kg}(P=0.04)$.

\section{Metabolic findings}

Due to the small but significant weight reduction $(P<0.05)$ that occurred in the subjects, statistical analyses of the biochemical results were performed in three groups: whole 
Table 1. Baseline and post-intervention macronutrient intakes of the study population* (Mean values with their standard errors)

\begin{tabular}{|c|c|c|c|c|c|}
\hline & \multicolumn{2}{|c|}{ Baseline (n 18) } & \multicolumn{2}{|c|}{ Post-intervention ( $n$ 18) } & \multirow{2}{*}{$\begin{array}{c}\text { Statistical significance } \\
\text { of effect (Student's } t \text { test): } P\end{array}$} \\
\hline & Mean & SEM & Mean & SEM & \\
\hline Energy (MJ/d) & $13 \cdot 2$ & 0.5 & 12.9 & 0.5 & 0.51 \\
\hline $\mathrm{CHO}$ (\% energy) & 46 & 1.6 & 46 & $2 \cdot 1$ & 0.98 \\
\hline Fat (\% energy) & 34 & 1.5 & 32 & 1.6 & 0.15 \\
\hline Protein (\% energy) & 15 & 0.6 & 16 & 0.6 & 0.22 \\
\hline $\operatorname{NSP}(g)$ & 20 & 1.6 & 21 & 1.9 & 0.50 \\
\hline GI & 80 & 1.9 & $70^{*}$ & $1 \cdot 7$ & 0.002 \\
\hline
\end{tabular}

$\mathrm{CHO}$, carbohydrate; GI, glycaemic index.

${ }^{*}$ For details of subjects and procedures, see p. 366

population (Table 3); weight-reducers (Table 4); weightincreasers and no change (Table 4). This sub-analysis was performed to determine whether biochemical changes were due to the dietary intervention per se or the weightreducing effect of the dietary intervention. The results showed that biochemical changes between groups $(\Delta$ change) were not significantly different. However, the effects of weight loss on the biochemical outcomes cannot be dismissed, as the within-group comparison analysis (between baseline and post-intervention periods) shows significant decreases in the glucose $(P<0.05)$ and insulin iAUC $(P<0.05)$ in the weight-decreaser group. This did not occur in the weight increaser and no change group. The biochemical results are shown for the group as a whole (Table 3 ).

The fasting metabolic variables at baseline and postintervention are shown in Table 2. There was a trend towards a decrease in total serum cholesterol in the group (baseline 4.5 (SEM 0.2) $v$. post-intervention 4.3 (SEM 0.2) $\mathrm{mmol} / \mathrm{l}, P=0.07$ ) and a significant decrease in fasting LDL-cholesterol following the intervention (baseline $3.2(\operatorname{SEM} 0 \cdot 2) \quad v$. post-intervention 2.8 (SEM 0.2) $\mathrm{mmol} / \mathrm{l}, P=0 \cdot 01)$. There were no other significant changes in fasting biochemical variables.
The results of the OGTT indicated that the dietary intervention produced significant improvements in the subjects' insulin sensitivity (Table 3 ). The insulin sensitivity index increased significantly post-intervention (baseline 7.8 (SEM 1.1) $v$. post-intervention 9.7 (SEM 1.1), $P=0.02$ ). In addition, there was a significant decrease in the insulin iAUC (baseline 30.8 (SEM 4.2) v. post-intervention 23.7 (SEM $3 \cdot 3$ ) $\mathrm{nmol} / \mathrm{min}$ per litre, $P<0 \cdot 01$ ). Further analysis showed that the early insulin secretion appeared to be most affected by the intervention, seen through significant reductions in the insulin concentrations at $30 \mathrm{~min}$ (baseline 319.0 (SEM 30.7) $v$. post-intervention 262.9 (SEM 35.2) pmol/l, $P=0.03$ ) and $60 \mathrm{~min}$ (baseline 331.3 (SEM 36.3) $v$. post-intervention $280 \cdot 0$ (SEM 39.5) $\mathrm{pmol} / \mathrm{l}, P=0 \cdot 02$ ). The insulin concentration at $2 \mathrm{~h}$ of the OGTT showed a trend towards reduction post-intervention, but this did not reach statistical significance (baseline 204.7 (SEM 43.3) $v$. post-intervention $156 \cdot 9$ (SEM 27.4) pmol/1, $P=0.08$ ).

The glucose iAUC was reduced by the intervention, but this did not reach statistical significance (baseline 257.1 (SEM 44.5) $v$. post-intervention 215.1 (SEM 33.6) mmol/ min per litre, $P=0 \cdot 08$ ). In accordance with the insulin changes, it was the early glucose uptake that was most affected by the intervention with the $30 \mathrm{~min}$ glucose

Table 2. Baseline and post-intervention anthropometric and biochemical characteristics of the study population† (Mean values with their standard errors)

\begin{tabular}{|c|c|c|c|c|c|}
\hline & Mean & SEM & Mean & SEM & $\begin{array}{c}\text { Statistical significance } \\
\text { of effect (Student's } t \text { test): } P\end{array}$ \\
\hline Weight (kg) & $87 \cdot 3$ & 3.08 & $86 \cdot 7^{\star}$ & $3 \cdot 12$ & 0.04 \\
\hline Height $(\mathrm{m})$ & $1 \cdot 80$ & 0.02 & $1 \cdot 80$ & 0.02 & Constant \\
\hline BMI $\left(\mathrm{kg} / \mathrm{m}^{2}\right)$ & $27 \cdot 3$ & 1.03 & $27 \cdot 1$ & 1.06 & 0.09 \\
\hline Total cholesterol (mmol/l) & 4.5 & $0 \cdot 2$ & $4 \cdot 3$ & 0.2 & 0.07 \\
\hline HDL-cholesterol (mmol/l) & 0.8 & 0.03 & 0.8 & 0.03 & 0.43 \\
\hline LDL-cholesterol (mmol/l) & $3 \cdot 2$ & $0 \cdot 2$ & $2 \cdot 8^{*}$ & 0.2 & 0.01 \\
\hline Fasting glucose (mmol/l) & $5 \cdot 1$ & 0.2 & $5 \cdot 1$ & 0.2 & 0.55 \\
\hline Fasting TG (mmol/l) & $1 \cdot 0$ & 0.1 & $1 \cdot 1$ & 0.2 & 0.81 \\
\hline Fasting insulin (pmol/l) & 62.4 & $10 \cdot 0$ & $59 \cdot 8$ & $12 \cdot 2$ & 0.68 \\
\hline
\end{tabular}

TG, triacylglycerol; NEFA, non-esterified fatty acid.

Mean values were significantly different from those at baseline: ${ }^{*} P<0.05$

†For details of subjects and procedures, see p. 366. 
Table 3. Baseline and post-intervention oral glucose tolerance test results of the study population† (Mean values with their standard errors)

\begin{tabular}{|c|c|c|c|c|c|}
\hline & \multicolumn{2}{|c|}{ Baseline ( $n$ 18) } & \multicolumn{2}{|c|}{ Post-intervention ( $n$ 18) } & \multirow{2}{*}{$\begin{array}{c}\text { Statistical significance } \\
\text { of effect (Student's } t \text { test): } P\end{array}$} \\
\hline & Mean & SEM & Mean & SEM & \\
\hline Glucose iAUC (mmol/min per litre) & $257 \cdot 1$ & $44 \cdot 5$ & $215 \cdot 1$ & $33 \cdot 6$ & 0.08 \\
\hline Insulin iAUC (nmol/min per litre) & $30 \cdot 8$ & $4 \cdot 2$ & $23 \cdot 7^{\star}$ & $3 \cdot 3$ & 0.003 \\
\hline NEFA iAUC (mmol/min per litre) & 48.9 & 6.5 & $51 \cdot 8$ & 4.4 & 0.6 \\
\hline TG iAUC (mmol/min per litre) & $16 \cdot 5$ & $4 \cdot 0$ & $8 \cdot 7^{*}$ & 3.5 & 0.01 \\
\hline ISI & $7 \cdot 8$ & $1 \cdot 1$ & $9 \cdot 7^{\star}$ & $1 \cdot 1$ & 0.02 \\
\hline
\end{tabular}

iAUC, incremental area under the curve (calculated using the trapezoidal rule); NEFA, non-esterified fatty acid; TG, triacylglycerol; ISI, insulin sensitivity index.

Mean values were significantly different from those at baseline: ${ }^{\star} P<0.05$.

†For details of subjects and procedures, see p. 366.

concentration being considerably reduced post-intervention (baseline 8.3 (SEM 0.4) v. post-intervention 7.8 (SEM 0.4) $\mathrm{mmol} / \mathrm{l}, P=0 \cdot 09)$.

Plasma triacylglycerol concentrations were significantly lower following the intervention (baseline 16.5 (SEM 4.0) $v$. post-intervention $8.7(\mathrm{SEM} 3.5) \mathrm{mmol} / \mathrm{min}$ per litre, $P=0 \cdot 01$ ), although there were no significant changes in NEFA concentrations post-intervention (baseline 48.9 (SEM 6.5) $v$. post-intervention 51.8 (SEM 4.4) $\mathrm{mmol} / \mathrm{min}$ per litre, $P=0.63$ ).

\section{Muscle triacylglycerol}

A representative spectrum from the soleus muscle of one of the subjects is shown in Fig. 1. The subjects' IMCL storage levels are shown in Table 5. There were no significant associations (Pearson's correlation) found between IMCL storage and BMI, or IMCL and insulin sensitivity. Following 4-weeks low-GI diet intervention, IMCL concentrations showed no significant changes in any of the three muscle groups (Table 5).

\section{Discussion}

Insulin resistance is a state that predisposes to CHD and type 2 diabetes, and is the common factor that links these two diseases. A number of studies, using biopsy and in vivo magnetic resonance spectroscopy, have shown that insulin resistance is strongly correlated with muscle IMCL content (Forouhi et al. 1999). Similar relationships have been reported in animal studies (Koyama et al. 1997; Laybutt et al. 1997; Oakes et al. 1997). Moreover, in several of these studies, IMCL was shown to correlate more strongly with insulin resistance than other measurements of body adiposity, including visceral fat. There is, however, an interesting paradox to these findings: trained athletes are found to have relatively high IMCL storage and insulin sensitivity compared with untrained subjects (Goodpaster et al. 2001). The published results on IMCL storage and insulin resistance would predict that athletes would have low IMCL storage because they are highly insulin sensitive. In the present study, we have failed to find any significant correlations between either IMCL and insulin sensitivity or IMCL and BMI. This discrepancy in results between the present study and the previously published reports may be due to methodological errors. Previously, correlational analysis has been performed on populations consisting of two groups (insulin resistant and controls) rather than a continuum of results from one group. Performing correlational analysis on populations consisting of two distinctly different groups produces falsely significant associations.

Despite the wealth of published correlative studies, there is a paucity of interventional research that can help to establish cause and effect, especially in human subjects. In the present study we have shown that, using a 4-week low-GI diet intervention, insulin sensitivity can be positively altered independently of IMCL storage. The present results suggest that IMCL levels per se may not be the prime determinant of insulin sensitivity in healthy human subjects. Indeed the work of Voshol et al. (2001) appears to support our present findings by showing that overexpression of human lipoprotein lipase in muscle increases IMCL accumulation, but does not affect whole-body or muscle-specific insulin-mediated uptake.

At present, although the relationship between IMCL and insulin sensitivity is well established, intervention studies are both limited and relatively inconclusive. Evidence from rodent studies shows that rats made insulin resistant, using a high-fat diet, increase their IMCL storage (Kraegen et al. 1991), while treatment with an insulin-sensitising pharmaceutial agent leads to a reduction in IMCL storage (Sreenan et al. 1999). However, marked reduction in other fat depots, including liver and pancreas were also observed, making it difficult to separate the contribution of IMCL to the overall changes in insulin sensitivity. This appears to be also true in animal studies, where food restriction led to a reduction in IMCL and improvement in insulin sensitivity (Man et al. 2002; Ohneda et al. 2002). Thus, the changes in insulin sensitivity reported in these studies may in part arise from modulations in fat content (or related components) in depots others than IMCL, including hepatic and pancreatic lipids.

Intervention studies aimed at manipulating IMCL and insulin sensitivity in human volunteers are rather limited. Goodpaster et al. (2000) have shown a significant decrease in IMCL in obese subjects, following weight loss, while Mingrone et al. (2001), using muscle biopsies, found a reversal of insulin resistance and a reduction in IMCL in subjects with morbid obesity following significant weight 


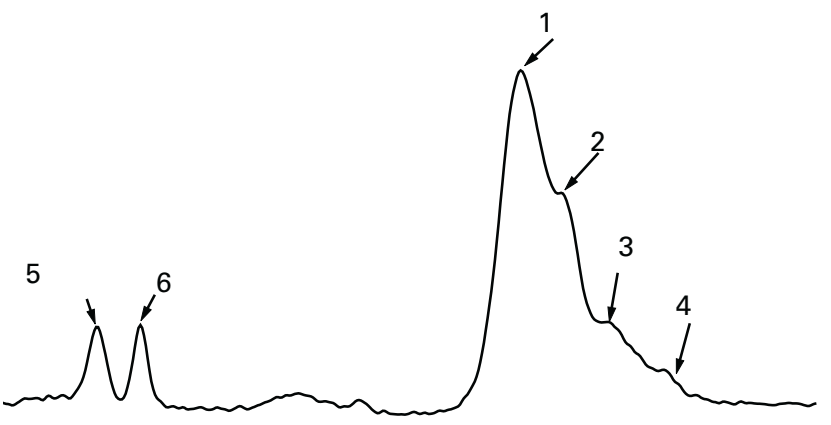

3.0

$2 \cdot 0$

$1 \cdot 0$

Chemical shift (ppm)

Fig. 1. ${ }^{1} \mathrm{H}$-Magnetic resonance spectrum of the soleus muscle: a typial proton spectrum from the soleus muscle. For details of procedures, see p. 366. The lipid resonances are shown between 0.9 and $1.5 \mathrm{ppm}$. Peaks 1 and 3 refer to extramyocellular lipid; peaks 2 and 4 refer to intramyocellular lipid (IMCL); peaks 5 and 6 have been assigned to choline-containing metabolites (principally carnitine) and total creatine $(\mathrm{Cr})$ (phosphocreatine and creatine) respectively (Schik et al. 1993); peak 6 refers total creatine resonance $(3.02 \mathrm{ppm})$ that is used for quantification of the lipid peaks (IMCL : $\mathrm{Cr}_{\text {total }}$ ratio).

loss. However, as with animal studies, decreases in IMCL were accompanied by changes in other fat depots, and presumably adipose-tissue-related factors, which in turn may independently influence insulin sensitivity. The study of Malenfant et al. (2001) showed no significant effect on either insulin sensitivity or IMCL storage using similar weight loss interventions in obese subjects. However, they did report a trend towards improved insulin sensitivity with no significant changes in IMCL (Malenfant et al. 2001). Other human interventional studies have concentrated on alterations in insulin sensitivity through the use of artificially increased circulating NEFA levels (Roden et al. 1996; Boden et al. 2001; Brechtel et al. 2001). Significant changes in insulin sensitivity and IMCL levels were observed following Intralipid infusion. However, decreases in circulating NEFA did not lead to significant changes in IMCL (Brechtel et al. 2001). Furthermore, Krssak et al. (2000) have reported that elevation of circulating NEFA without hyperinsulaemia did not alter IMCL levels. This suggests that changes in IMCL may only arise as a consequence of altered insulin status (or other adipose tissue and lipid factors) rather than being the cause. This may explain in part the delay in IMCL accumulation observed in many Intralipid infusion studies, where hyperinsulinaemia may lead to changes in some circulating factor, which in turn may lead to changes in lipid uptake in skeletal muscle (Furler et al. 2001).

In the present study, we used a 4-week low-GI-diet intervention to induce an increase in insulin sensitivity, as shown by reduced insulin and glucose iAUC, and increased insulin sensitivity index. The dietary intervention also significantly improved the subjects' fasting lipid profiles and postprandial triacylglycerol metabolism, but did not alter NEFA. A critical observation in the insulin resistance model is the relationship between NEFA and tissue insulin sensitivity, while the work of Brechtel et al. (2001) also suggests a relationship between NEFA and IMCL. Previously, Wolever et al. (1995) have suggested that low-GI diets improve insulin sensitivity by reducing postprandial NEFA rebounding. This is believed to be due to the lower and attenuated glucose and insulin responses that occur after ingesting low-GI carbohydrates as opposed to high-GI carbohydrates. By attenuating the glucose and insulin responses, NEFA suppression is extended and rebounding levels are substantially reduced (Wolever et al. 1995). In our present study, we saw no significant changes in fasting or postprandial NEFA metabolism, probably because our subjects had normal physiology and therefore did not experience significant NEFA rebounding. NEFA play a central role in the theory by which IMCL storage may be a cause of insulin resistance (Randle et al. 1963). However, in the current study we failed to detect any alterations in NEFA, and this may partly explain why we did not detect any significant changes in IMCL storage.

We also must consider the possibility that an aspect of the study protocol may be responsible for the lack of change in IMCL concentrations, for example the suitability of the length or intensity of the intervention. However, we are confident that these factors do not impact on the results of our present study. Several studies have shown positive effects on insulin sensitivity from the same duration (3 weeks) of low-GI manipulation, even though the changes in GI were much larger (20-30\% reduction) compared with the $15 \%$ achieved by our present subjects (Wolever et al. 1992; Frost et al. 1998). This attenuated change in GI is not surprising given that our present subject group had relatively low-GI diets at baseline and that one of the aims of the protocol was that the manipulation was achievable

Table 5. Baseline and post-intervention intramyocellular lipid storage levels of the study population* $\dagger$ (Mean values with their standard errors)

\begin{tabular}{|c|c|c|c|c|c|}
\hline & \multicolumn{2}{|c|}{ Baseline ( $n$ 18) } & \multicolumn{2}{|c|}{$\begin{array}{l}\text { Post-intervention } \\
\quad(n 18)\end{array}$} & \multirow{2}{*}{$\begin{array}{l}\text { Statistical significance } \\
\text { of effect (Student's } t \text { test): } P\end{array}$} \\
\hline & Mean & $\overline{\text { SEM }}$ & Mean & $\overline{\text { SEM }}$ & \\
\hline Soleus & $17 \cdot 1$ & 1.62 & $15 \cdot 9$ & 2.02 & 0.51 \\
\hline Tibialis & 6.5 & 0.72 & $6 \cdot 6$ & 0.73 & 0.78 \\
\hline Gastrocnemius & $12 \cdot 0$ & 1.56 & $12 \cdot 4$ & 1.81 & 0.70 \\
\hline
\end{tabular}

${ }^{*}$ For details of subjects and procedures, see p. 366.

† Muscle triacylglycerol values are expressed as intramyocellular lipid:total creatine ratios for three muscle groups. 
within the habitual diet. To achieve greater reductions in GI would have necessitated using foods outside of the proposed protocol. It is important to point out that even with this relatively smaller reduction in GI, the present increase in insulin sensitivity $(21 \%)$ is comparable with the $23 \%$ increase reported by Frost et al. (1998) following a $20 \%$ reduction in GI. This suggests that the more intense manipulation achieved by Frost et al. (1998) had no greater effect on insulin sensitivity, and raises the possibility of a plateau occurring in which no greater improvements in insulin sensitivity occur. In addition, related to the study protocol, consideration must be given to the methods that were used to assess the subjects' insulin sensitivity. The OGTT-based insulin sensitivity index is a general assessment of wholebody glucose disposal: it does not allow for specific assessment of muscle insulin sensitivity. A more precise assessment of muscular glucose disposal in the current study may have identified changes in muscle insulin sensitivity that were not recognised with the current techniques.

We propose that the effects on insulin sensitivity induced by the dietary intervention may be through effects on factors other than IMCL, which are capable of affecting whole-body insulin sensitivity. Thorburn et al. (1993) found that highly fermentable carbohydrates improved glycaemia in healthy subjects through reducing hepatic glucose production and, in general, low-GI foods are high in fermentable carbohydrate. Therefore, this dietary manipulation may have had its insulin-sensitising effects on the liver and have resulted in reduced hepatic gluconeogenesis. Enhanced suppression of hepatic gluconeogenesis during an OGTT would be expected to result in reduced glucose and insulin iAUC as found in our present study. Similarly, Abel et al. (2001) have provided evidence for an internal communication pathway between adipose tissue, liver and muscle in rodents. Mice with GLUT4 deficiency and insulin resistance selectively in the adipose tissue have additional loss of insulin sensitivity in their muscle and liver even though GLUT4 expression was preserved in these tissues. It was proposed that these indirect changes in insulin sensitivity occurred through an unidentified adipocyte-derived molecule that affects insulin action in other tissues. This inter-tissue communication pathway is an alternative possible mode of action by which the low-GI dietary manipulation improved insulin sensitivity.

In conclusion, we have provided evidence for a dietary manipulation of insulin sensitivity independently of IMCL storage in a healthy male cohort. Further work is required to ascertain whether these findings also occur in other subject groups, particularly insulin-resistant subjects such as those with type 2 diabetes or CHD. These individuals would be expected to have elevated IMCL concentrations at baseline. This may alter the reaction to a manipulation of insulin sensitivity, such that there is a possible threshold for which IMCL impact on insulin sensitivity.

\section{Acknowledgements}

We would like to thank Dr T. Aitman for helpful discussion. W. S. D. is a Wellcome Trust Clinical Training Fellow.
The authors would like to thank the MRC and Marconi Medical Systems (Cleveland, OH, USA) for their support during this study.

\section{References}

Abel ED, Peroni OD, Kim JK, Kim Y-B, Boss O, Hadro E, Minnemann T, Shulman GI \& Kahn BB (2001) Adipose-selective targeting of the GLUT4 gene impairs insulin action in musle and liver. Nature 409, 729-733.

Albano JD, Ekins RP, Maritz G \& Turner RC (1972) A sensitive, precise radioimmunoassay of serum insulin relying on charcoal separation of bound and free hormone moieties. Acta Endocrinology 70, 487-509.

Boden G, Lebed B, Schatz M, Homko C \& Lemieux S (2001) Effects of acute changes of plasma free fatty acids on intramyocellular free fatty acids and insulin resistance in healthy subjects. Diabetes 50, 1612-1617.

Brechtel K, Dahl DB, Machann J, Bachmann OP, Wenzel I, Maier T, Claussen C, Haring HU, Jacob S \& Schick F (2001) Fast elevation of the intramyocellular lipid content in the presence of circulating free fatty acids and hyperinsulinemia: A dynamic ${ }^{1} \mathrm{H}-\mathrm{MRS}$ study. Magnetic Resonance in Medicine 45, 179-183.

Daly ME, Vale C, Walker M, Alberti KG \& Mathers JC (1997) Dietary carbohydrates and insulin sensitivity: a review of the evidence and clinical implications. American Journal of Clinical Nutrition 66, 1072-1085.

Department of Health (1991) Dietary Reference Values for Food Energy and Nutrients for the United Kingdom: Report of the Panel on Dietary Reference Committee on Medical Aspects of Food Policy. London: H. M. Stationery Office.

Falholt K, Jensen I, Lindkaer JS, Mortensen H, Volund A, Heding LG, Noerskov PP \& Falholt W (1988) Carbohydrate and lipid metabolism of skeletal muscle in type 2 diabetic patients. Diabetic Medicine 5, 27-31.

Forouhi NG, Jenkinson G, Thomas EL, Mullik S, Mierisova S, Bhonsle SM, Keigue PM \& Bell JD (1999) Relation of triglyceride stores in skeletal muscle cells to central obesity and insulin sensitivity in European and South Asian men. Diabetologia 42, 932-935.

Foster PK \& Miller JB (1995) International tables of glycemic index. American Journal of Clinical Nutrition 62, 871S-890S.

Frost G, Keogh B, Smith D, Akinsanya K \& Leeds A (1996) The effect of low-glycemic carbohydrate on insulin and glucose response in vivo and in vitro in patients with coronary heart disease. Metabolism 45, 669-672.

Frost G, Leeds A, Dore C, Madeiros S, Brading S \& Dornhorst A (1999) Glycaemic index as a determinant of serum HDLcholesterol concentration. Lancet 353, 1045-1048.

Frost G, Leeds A, Trew G, Margara R \& Dornhorst A (1998) Insulin sensitivity in women at risk of coronary heart disease and the effect of a low glycaemic diet. Metabolism 47, $1245-1251$.

Furler SM, Poynten A, Kriketos AD, Lowy AJ, Ellis BA, Maclean EL, Courtenay BG, Kraegen EW, Campbell LV \& Chisholm DJ (2001) Independent influences of central fat and skeletal muscle lipids on insulin sensitivity. Obesity Research 9, $535-543$

Goodpaster BH, He J, Watkins S \& Kelley DE (2001) Skeletal muscle lipid content and insulin resistance: evidence for a paradox in endurance-trained athletes. Journal of Clinical Endocrinology and Metabolism 86, 5755-5761.

Goodpaster BH, Theriault R, Watkins SC \& Kelley DE (2000) Intramusular lipid content is increased in obesity and decreased by weight loss. Metabolism 49, 467-472. 
Jacob S, Machann J, Rett K, Brechtel K, Volk A, Renn W, Maerker E, Matthaei S, Schick F, Claussen C \& Haring H (1999) Association of increased myocellular lipid content with insulin resistance in lean nondiabetic offspring of type II diabetic subjects. Diabetes 48, 1113-1119.

Jenkins DJ, Wolever TM, Buckley G, Lam KY, Giudici S, Kalmusky J, Jenkins AL, Patten RL, Bird J, Wong GS \& Josse RG (1988) Low-glycemic-index starchy foods in the diabetic diet. American Journal of Clinical Nutrition 48, $248-254$.

Koyama K, Chen G, Lee Y \& Unger RH (1997) Tissue triglycerides insulin resistance and insulin production: implications for hyperinsulinemia of obesity. American Journal of Physiology 273, E708-E713.

Kraegen EW, Clark PW, Jenkins AB, Daley EA, Chisholm DJ \& Storlien LH (1991) Development of muscle insulin resistance after liver insulin resistance in high-fat-fed rats. Diabetes $\mathbf{4 0}$, $1397-1403$.

Krssak M, Krebs M, Stingl H, Mlynarik V, Gruber S, Moser E \& Roden M (2000) Intramyocellular lipid (IMCL) stores before and after lipid infusion. Proceedings of the International Society for Magnetic Resonance in Medicine 8, Abstr.

Krssak M, Petersen KF, Dresner A, DiPietro L, Vogel SM, Rothman DL, Shulman GI \& Roden M (1999) Intramyocellular lipid concentrations are correlated with insulin sensitivity in humans: an H-1 NMR spectroscopy study. Diabetologia 42, 113-116.

Laybutt DR, Chisholm DJ \& Kraegen EW (1997) Specific adaptations in muscle and adipose tissue in response to chronic systemic glucose oversupply in rats. American Journal of Physiology 273, E1-E9.

Liu S, Willett W, Stampfer MJ, Hu FB, Franz M, Sampson L, Hennekens CH \& Manson JE (2000) A prospective study of dietary glycemic load carbohydrate intake and risk of coronary heart disease in US women. American Journal of Clinical Nutrition 71, 1455-1461, Abstr.

Magnetic Resonance User Interface (2002) http://carbon.uab.es/ mrui

Malenfant P, Tremblay A, Doucet E, Imbeault P, Simoneau JA \& Joanisse DR (2001) Elevated intramyocellular lipid concentration in obese subjects is not reduced after diet and exercise training. American Journal of Physiology 280, E632-E639.

Man ZW, Hirashima T, Mori S \& Kawano K (2002) Decrease in triglyceride accumulation in tissues by restricted diet and improvement of diabetes in Otsuka Long-Evans Tokushima fatty rats, a non-insulin-dependent diabetes model. Metabolism 49, $108-114$.

Matsuda M \& Defronzo R (1999) Insulin sensitivity indices obtained from oral glucose tolerance testing comparison with the euglycemic insulin clamp. Diabetes Care 22, $1462-1470$

Mingrone G, Bertuzzi A, Capristo E, Greco A, Manco M, Pietrobelli A, Salinari S \& Heymsfield SB (2001) Unreliable use of standard muscle hydration value in obesity. American Journal of Physiology 280, E365-E371.

Nelson M, Atkinson M \& Meyer J (1997) A Photographic Atlas of Food Portion Sizes. London: Ministry of Agriculture, Fisheries and Food.

Oakes ND, Cooney GJ, Camilleri S, Chisholm DJ \& Kraegen EW (1997) Mechanisms of liver and muscle insulin resistance induced by chronic high-fat feeding. Diabetes $\mathbf{4 6}$, $1768-1774$.

Ohneda M, Inman LR \& Unger RH (2002) Caloric restriction in obese pre-diabetic rats prevents beta-cell depletion loss of betacell GLUT2 and glucose incompetence. Diabetologia 38, $173-179$.
Pan DA, Lillioja S, Kriketos AD, Milner MR, Baur LA, Bogardus C, Jenkins AB \& Storlien LH (1997) Skeletal muscle triglyceride levels are inversely related to insulin action. Diabetes $\mathbf{4 6}$, 983-988.

Phillips DI, Caddy S, Ilic V, Fielding BA, Frayn KN, Borthwick AC \& Taylor R (1996) Intramuscular triglyceride and muscle insulin sensitivity: evidence for a relationship in nondiabetic subjects. Metabolism 45, 947-950.

Randle PJ, Hales CN, Garland PB \& Newsholme EA (1963) The glucose fatty-acid cycle: Its role in insulin sensitivity and the metabolic disturbances of diabetes mellitus. Lancet i, 785-789.

Reaven GM (1994) Syndrome X: 6 years later. Journal of Internal Medicine i Suppl. 736, 13-22.

Reaven GM (1995) Pathophysiology of insulin resistance in human disease. Physiology Reviews 75, 473-486.

Rico-Sanz J, Hajnal JV, Thomas EL, Mierisova S, Ala-Korpela M \& Bell JD (1998) Intracellular and extracellular skeletal muscle triglyceride metabolism during alternating intensity exercise in humans. Journal of Physiology 510(pt 2), 615-622.

Roche HM (1999) Dietary carbohydrate and triacylglycerol metabolism. Proceedings of the Nutrition Society 58, 201-207.

Roden M, Price TB, Perseghin G, Petersen KF, Rothman DL, Cline GW \& Shulman GI (1996) Mechanism of free fatty acid-induced insulin resistance in humans. Journal of Clinical Investigation 97, 2859-2865.

Salmeron J, Ascherio A, Rimm EB, Colditz GA, Spiegelman D, Jenkins DJ, Stampfer MJ, Wing AL \& Willett W (1997a) Dietary fiber, glycemic load and risk of NIDDM in men. Diabetes Care 20, 545-550.

Salmeron J, Manson JE, Stampfer MJ, Colditz GA, Wing AL \& Willett WC (1997b) Dietary fiber, glycemic load and risk of non-insulin-dependent diabetes mellitus in women. Journal of the American Medical Association 277, 472-477.

Saris WH, Asp NGL, Bjorck I, Blaak E, Bornet F, Brouns F, Frayn KN, Furst P, Riccardi G, Roberfroid M \& Vogel M (1998) Functional food science and substrate metabolism. British Journal of Nutrition 80, S47-S75.

Schick F, Eismann B, Jung WI, Bongers H, Bunse M \& Lutz O (1993) Comparison of localized proton NMR signals of skeletal muscle and fat tissue in vivo: two lipid compartments in muscle tissue. Magnetic Resonance in Medicine 29, $158-167$.

Schofield WN, Schofield C \& James WPT (1985) Basal metabolic rate-review and prediction. Human Nutrition: Clinical Nutrition 39, Suppl., 1-96.

Sreenan S, Keck S, Fuller T, Cockburn B \& Burant F (1999) Effects of troglitazone on substrate storage and utilization in insulin-resistant rats. American Journal of Physiology 276, E1119-E1129.

Stears AJ \& Byrne CD (2001) Adipocyte metabolism and the metabolic syndrome. Diabetes Obesity and Metabolism 3, $129-142$.

Storlien LH, Jenkins AB, Chisholm DJ, Pascoe WS, Khouri S \& Kraegen EW (1991) Influence of dietary fat composition on development of insulin resistance in rats. Relationship to muscle triglyceride and $n-3$ fatty acids in muscle phospholipids. Diabetes 40, 280-289.

Thomas EL, Frost G, Harrington T \& Bell JD (2001) Validation of "in body" bioelectrical impedance by whole body MRI. Proceedings of the Nutrition Society 60, 96A.

Thorburn A, Muir J \& Proietto J (1993) Carbohydrate fermentation decreases hepatic glucose output in healthy subjects. Metabolism 42, 780-785.

Torjesen PA, Birkeland KI, Anderssen SA, Hjermann I, Holme I \& Urdal P (1997) Lifestyle changes may reverse development 
of the insulin resistance syndrome. The Oslo Diet and Exercise Study: a randomized trial. Diabetes Care 20, 26-31.

Tremblay A (1995) Nutritional determinants of the insulin resistance syndrome. International Journal of Obesity 19, Suppl., S60-S68.

Van Dam RM, Visscher AW, Feskens EJ, Verhoef $\mathrm{P}$ \& Kromhout D (2000) Dietary glycaemic index in relation to metabolic risk factors and incidence of coronary heart disease: the Zirtphen Elderly Study. European Journal of Clinical Nutrition 54, 726-731.

van den Boogaart A, van Heke P, van Huffel S, GraveronDemilly D, van Ormondt D \& de Beer R (1996) MRUI: a graphical user interface for accurate routine MRS data analysis. In Proceedings of the ESMRMB, 13th Annual Meeting of the ESMRMB, pp. 318.

Voshol PJ, Jong MC, Dahlmans VE, Kratky D, Levak-Frank S,
Zechner R, Romijn JA \& Havekes LM (2001) In muscle-specific lipoprotein lipase-overexpressing mice muscle triglyceride content is increased without inhibition of insulin-stimulated whole-body and muscle-specific glucose uptake. Diabetes 50, 2585-2590.

Wolever T, Jenkins DJ, Vuksan V, Jenkins AL, Buckley G, Wong GS \& Josse RG (1992) Beneficial effect of a low glycaemic index diet in type 2 diabetes. Diabetic Medicine 9, 451-458, Abstr.

Wolever TM, Bentum WA \& Jenkins DJ (1995) Physiological modulation of plasma free fatty acid concentrations by diet. Metabolic implications in nondiabetic subjects. Diabetes Care 18, 962-970.

Wolever TM \& Jenkins DJ (1986) The use of the glycemic index in predicting the blood glucose response to mixed meals. American Journal of Clinical Nutrition 43, 167-172. 